\title{
Adjacent Segment Pathology: Progressive Disease Course or a Product of Iatrogenic Fusion?
}

\author{
Andrew Jack, Godefroy Hardy St-Pierre, Andrew Nataraj
}

\begin{abstract}
Objective: Cervical spine clinical adjacent segment pathology (CASP) has a reported $3 \%$ annual incidence and $26 \%$ ten-year prevalence. Its pathophysiology remains controversial, whether due to mechanical stress of a fusion segment on adjacent levels or due to patient propensity to develop progressive degenerative change. We investigate this relationship by comparing prevalence of CASP in traumatic and spondylotic patient cohorts. Method: A retrospective review of traumatic cervical spine fusion cases performed by the local group of neurosurgeons from 2004-2008 was completed. Surgery for CASP and presence of radiological adjacent segment pathology (RASP) were identified by telephone and electronic medical record (EMR) review, and compared to those in patients having elective cervical fusion for degenerative disease. Results: There was a higher proportion of males $(50 / 100$ vs. $37 / 46, p<0.001)$ in the traumatic group. Median age between groups was not significantly different (47 years in the trauma cohort, 50 years in the degenerative cohort; $\mathrm{p}>0.05$ ). Mean follow-up times were different (6.4 years in the trauma group, 7.1 years in the degenerative group; $\mathrm{p}<0.01$ ), although this was not thought to be clinically significant. The degenerative group was found to have a significantly higher reoperation rate for CASP $(10 / 100$ vs. 0/46, $p=0.031$, Fisher's Exact Test), and rate of RASP $(20 / 100$ vs. $1 / 32, p=0.025)$ Conclusion: This is the only cohort study to our knowledge comparing surgery for CASP in trauma patients to those with degenerative disease. A higher rate of repeat surgery in degenerative disease patients was found. This suggests that CASP is more related to patient factors predisposing to progressive degenerative disease and not increased mechanical stress.
\end{abstract}

RÉSUMÉ: Pathologie du segment adjacent : progression de la maladie ou conséquence de la fusion iatrogénique? Objectif: Selon la littérature, l'incidence annuelle d'une pathologie clinique du segment adjacent de la colonne cervicale (PSACC) est de $3 \%$ et sa prévalence à 10 ans de $26 \%$. Sa physiopathologie demeure controversée : est-ce dû au stress mécanique du segment de fusion sur les niveaux adjacents ou à la susceptibilité du patient à un processus dégénératif ? Nous avons étudié cette relation en comparant la prévalence d'une PSACC dans une cohorte de patients dont la pathologie initiale était un traumatisme et une cohorte de patients dont la pathologie initiale était une spondylose. Méthodologie: Nous avons procédé à une étude rétrospective des dossiers des patients traités par le groupe local de neurochirurgiens de 2004 à 2008 pour fusion de la colonne cervicale suite à un traumatisme. Nous avons identifié par téléphone, ainsi que par une revue des dossiers médicaux électroniques, les patients qui avaient subi une chirurgie pour une PSACC et la présence d'une pathologie du segment adjacent confirmé par radiologie (PSAR) chez ces patients. Nous avons comparé ces patients à ceux qui subissaient une fusion cervicale élective pour une maladie dégénérative. Résultats: Nous avons constaté qu'il y avait une proportion plus élevée d'hommes (50/100 par rapport à 37/46; p ) dans le groupe de patients qui présentaient une pathologie d'origine traumatique. L'âge médian n'était pas significativement différent entre les groupes (47 ans dans la cohorte traumatique et 50 ans dans la cohorte spondylotique; $p>0,05$ ). La durée du suivi était différente entre les groupes (6,4 ans dans le groupe traumatique et 7,1 ans dans le groupe dégénératif ; p <0,01), ce qui n'a pas été considéré comme étant significatif au point de vue clinique. Le taux de réintervention pour une PSACC ainsi que le taux de PSAR étaient significativement plus élevés dans le groupe de patients présentant une pathologie d'origine dégénérative (10/100 par rapport à 0/46; $\mathrm{p}=0,031$ par la méthode exacte de Fisher) et $(20 / 100$ par rapport à $1 / 32 ; p=0,025)$ respectivement. Conclusion: À notre connaissance, ceci constitue la seule étude de cohorte comparant la chirurgie pour une PSACC chez des patients dont la pathologie est d'origine traumatique et chez des patients présentant une maladie dégénérative. Nous avons constaté que le taux de réintervention était plus élevé chez les patients dont la pathologie était d'origine dégénérative, ce qui est en faveur de la présence de facteurs prédisposant à une maladie dégénérative progressive et non à un accroissement du stress mécanique chez les patients présentant une PSACC.

Keywords: Adjacent segment disease, adjacent segment pathology, clinical adjacent segment pathology, adjacent segment degeneration, anterior cervical discectomy and fusion, cervical fusion

doi:10.1017/cjn.2016.404

Can J Neurol Sci. 2017; 44: 78-82

\footnotetext{
From the Division of Neurosurgery, Department of Surgery, University of Alberta Hospital, Edmonton, Alberta, Canada. Received September 11, 2015. Final Revisions Submitted March 13, 2016.

Date of Acceptance June 9, 2016.

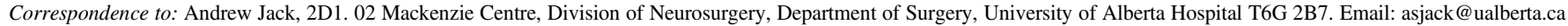




\section{INTRODUCTION}

Anterior cervical discectomy and fusion (ACDF) as a treatment for cervical spondylotic disease has been shown to be over $90 \%$ successful as treatment for radiculopathy and/or myelopathy. ${ }^{1}$ Due to its effectiveness, the consequences of this procedure have been thought to be of secondary importance. ${ }^{2}$ However, in their seminal paper, Hilibrand et al. reported a $3 \%$ annual incidence and $26 \%$ 10 -year prevalence of cervical spine CASP. ${ }^{3}$ As a result, the consequences of this procedure are likely more important than once thought. Controversy exists surrounding CASP etiology and pathophysiology, whether it is due to the altered mechanical stress of a fusion segment on adjacent levels, or to patient propensity to develop progressive degenerative change. To further our understanding of this relationship we compare the prevalence of CASP and RASP in traumatic and spondylotic patient cohorts.

\section{Materials AND Methods}

Ethics approval from the local institutional Health and Research Ethics Board was received for the completion of this study. Operative records and operative billing codes were searched for all patients having undergone a cervical fusion procedure performed by the local group of neurosurgeons between 2004 and 2008, to allow for at least five years follow-up. Chart review and an EMR database were used to collect patient clinical and demographic information, including patient age, gender, date of operation, operation performed, operative indication, and history of lumbar spine surgery for degenerative disease. The picture archive and communication system (PACS) was used to gather all pre-operative and post-operative radiological data for each case from plain radiographs (XR) and magnetic resonance imaging (MRI) of the cervical spine, including disc space height, end-plate sclerosis, osteophytosis, and intervertebral disc herniation with/without neural compression. Patients under eighteen years old, and patients with a pathological fracture (related to neoplastic or infectious etiology), ankylosing spondylitis, or DISH were excluded. Fifty male and fifty female patients undergoing elective cervical decompression and fusion procedures were included after identification through operative billing codes from 2004 to 2008, and age-matched to the trauma cohort. Patients were divided into two cohorts for comparison based on the initial operative indication: either traumatic instability, or elective decompression and fusion due to radiculopathy or myelopathy.

The occurrence of CASP was defined as a patient requiring a repeat operation for occurrence of radiculopathy/myelopathy at an adjacent cervical level. To limit ascertainment bias, trauma patients included were contacted to determine whether or not they had undergone repeat operation at another institution. Occurrence of RASP was quantified using a radiographic assessment scale previously shown to be both a reliable and objective tool for assessing cervical disc and facet joint degeneration. Because this scale has also proved to be experience- and discipline-independent, no inter-rater analysis was completed. ${ }^{4}$ The use and assessment of disc space height, extent of osteophyte formation, and degree of endplate sclerosis is a common and established method of quantifying cervical degeneration among published grading systems. ${ }^{4,5}$ RASP was classified as none, mild, moderate, or severe. ${ }^{4}$ Only patients demonstrating a two grade increase in degeneration were classified as having RASP; patients with moderate degeneration prior to surgery required only a one grade increase to be classified as having RASP (as previously reported). ${ }^{5}$ A Fisher's Exact Test was used to detect a statistically significant difference between the two cohorts for: prevalence of CASP, prevalence of RASP, prevalence of lumbar spine surgery, and gender. A t-test was used to compare age and follow-up period. Statistical significance was set at a p-value of less than 0.05 .

The incidence and prevalence of CASP were calculated for each year using a life-table method and construction of a KaplanMeier survivorship curve..$^{3,6,7}$ The prevalence of CASP was defined as the proportion of patients who developed CASP over the given follow-up period. The annual incidence was defined as the proportion of patients, initially disease-free at the beginning of a year and subsequently developed CASP. Several studies have shown that patients who develop CASP also have a propensity for developing degenerative disease elsewhere in their spine. ${ }^{8}$ Thus the number of lumbar spine operations for degenerative disease was recorded as a surrogate marker for CASP development and RASP.

\section{Results}

Forty-six traumatic cervical fusion patients were identified. Baseline characteristics are outlined in Table 1. The mean and median age for the cohort was 45.6 and 47 years, respectively. The majority of patients were male $(37 / 46,80.4 \%)$. The average length of follow-up was 6.4 years. A total of 51 procedures were completed: 32 via an anterior approach, 14 via a posterior approach, and 5 additional operations for delayed instability after anterior approach requiring circumferential stabilization. The majority of trauma patients identified had undergone a singlelevel fusion $(91.3 \%)$. There were no patients identified who required repeat operation for CASP development, nor were any identified who had undergone a separate lumbar spine surgery for degenerative disease. Thirty-two patients $(70.0 \%)$ had radiological imaging completed at a mean time of 25 months and median 13 months (range 4-83 months) post-operatively. One patient $(3.1 \%)$ had developed RASP.

One hundred consecutive patients (50 male and 50 female) undergoing single-level ACDF for spondylotic disease between 2004 and 2008 were included. Baseline characteristics for these patients are outlined in Table 1 . The mean and median age were

Table 1: Baseline clinical and technical characteristics from traumatic and degenerative patients

\begin{tabular}{l|c|c|c}
\hline Factor & $\begin{array}{c}\text { Traumatic } \\
\text { Patients (\%) }\end{array}$ & $\begin{array}{c}\text { Degenerative } \\
\text { Patients (\%) }\end{array}$ & P-value \\
\hline Gender & & & \\
\hline Male & $37 / 46(80.4)$ & $50 / 100(50.0)$ & $<0.01$ \\
\hline Female & $9 / 46(19.6)$ & $50 / 100(50.0)$ & 0.02 \\
\hline Age (median) & 47.0 & 50.0 & 0.08 \\
\hline Follow-up (years) & 6.4 & 7.1 & $<0.01$ \\
\hline Surgical Approach & & & $<0.01$ \\
\hline Anterior & $27 / 46(58.7)$ & $110 / 114(9.6)$ & $<0.01$ \\
\hline Posterior & $14 / 46(30.4)$ & $4 / 114(3.5)$ & $<0.01$ \\
\hline Circumferential & $5 / 46(10.9)$ & $0 / 114(0.0)$ & $<0.01$ \\
\hline Single-level fusion & $42 / 46(91.3)$ & $100 / 100(100.0)$ & \\
\hline
\end{tabular}


49.9 and 50-years old, respectively. The average length of followup was 7.1 years. A total of 114 procedures were completed: 110 via an anterior approach, and 4 via a posterior approach. Ten patients $(10.0 \%)$ required a second operation at a mean 3.6-years after the index operation for CASP development. Two patients required a third operation for CASP at a mean 7 years after the index operation. Seven patients $(7.0 \%)$ had also had lumbar spine surgery for degenerative disease. All patients had radiological imaging completed at a mean time of 38 months and median 33 months post-operatively (range, 2-122 months). Twenty patients $(20.0 \%)$ had developed RASP.

In comparing the two cohorts, there was a higher proportion of males in the trauma group $(80.4 \%$ vs. $50.0 \%, \mathrm{p}<0.01)$. However, no significant difference was found in CASP development between genders in the entire patient population (4/87 males vs. $6 / 59$ females, $p=0.32$ ), nor in the degenerative cohort (4/50 males vs. $6 / 50$ females, $p=0.74$ ). As such, the difference in gender between cohorts was not corrected for upon final analysis. There was a longer follow-up period in the degenerative cohort (6.4 years for the traumatic cohort vs. 7.1 years for the spondylotic cohort, $\mathrm{p}<0.01$ ). This difference, however, was not thought to be clinically significant; it was not corrected for in the analysis. Furthermore, a statistical difference was found between the two cohorts with respect to posterior and circumferential fixation $(\mathrm{p}<0.01)$, but since previous studies have not shown a relationship between surgical approach and CASP this was also not corrected for. ${ }^{9-12}$ There was also no significant difference in age between the two groups $(\mathrm{p}=0.17)$.

Although a higher overall number of patients underwent lumbar spine surgery in the degenerative cohort (7/100 vs. 0/46), this did not reach statistical significance $(\mathrm{p}=0.1)$. A post-hoc analysis found the power for the relationship between cervical CASP and patients also having lumbar spine surgery to be 0.17 . This indicates that many more patients would be required to properly determine if a relationship exists between the two factors. However, as shown in Table 2, there was a significant difference found in the number of patients requiring repeat operation for CASP development in the spondylotic patient cohort (10/100 vs. $0 / 46, p=0.03)$. Furthermore, significantly more spondylotic patients demonstrated RASP $(20 / 100$ vs. $1 / 32$, $\mathrm{p}=0.03)$.

\section{DiscuSSION}

Robinson and Smith were among the first to describe ACDF as a treatment for cervical spondylotic disease over 50-years ago. ${ }^{13}$ Due to its effectiveness, the long-term consequences of this procedure were once thought to be of minor importance. ${ }^{2}$ However, due to substantial rates of CASP development post-operatively, more emphasis and research is being done to investigate causes, risk factors, and treatment thereof. The primary purpose of this study was to further explore this issue and delineate the relationship between CASP development and iatrogenic fusion compared to spondylotic disease progression. Here we discuss reoperation due to CASP, coincident lumbar spine surgery, and RASP in traumatic and spondylotic patient cohorts.

\section{CASP Development}

CASP has been shown to develop at a relatively constant $3 \%$ annual incidence with a projected $26 \%$ of patients being affected over 10 years. $^{1-3,10,11,14,15}$ These values include those that are treated via non-operative methods. The prevalence of CASP

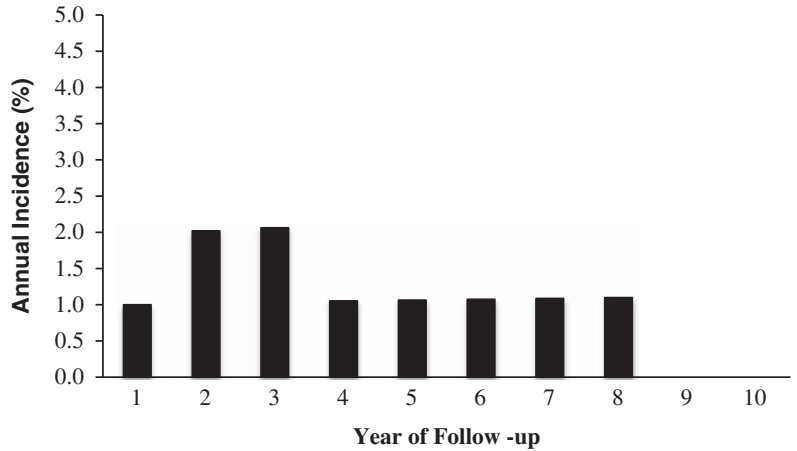

Figure 1: Bar graph showing the annual incidence of CASP development in the degenerative patient cohort.

requiring reoperation, however, has previously varied between $9 \%$ and $17 \% .^{1-3,14,16}$ This results in $1.5 \%-4.0 \%$ of patients requiring reoperation for CASP annually. The corresponding annual incidence calculated here was also in keeping with this range (Figures 1 and 2). In this study we found that $10 \%$ of elective ACDF patients required reoperation for CASP development, compared to $0 \%$ of trauma patients. Our results are on the lower end of what has been reported.

Several explanations could account for this difference, including differing practice patterns locally versus elsewhere. For example, local spine surgeons may simply be more conservative in managing this problem. The definition of CASP traditionally includes patients that develop the disease and are treated nonoperatively (or conservatively), leading to our reoperation rate for CASP being lower than elsewhere. Furthermore, the length of patient follow-up not only differs from that in other studies, but also slightly between the two cohorts. Although we believe that the difference between 6.4 and 7.1 years is not clinically significant, it is possible that a shorter follow-up time biases our results.

Ascertainment bias may also partially explain this difference. Our rate of reoperation in the degenerative group may be an underestimation. Although all of the trauma patients were contacted to determine whether they had undergone reoperation for CASP elsewhere (and thus not captured in our review), the spondylotic patients were not. This potential bias, however, could have lead to an underestimation of CASP in the degenerative

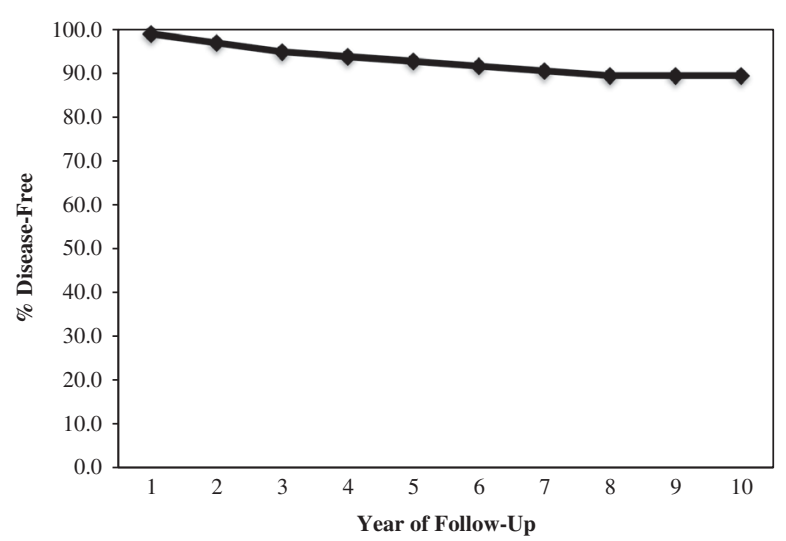

Figure 2: Kaplan-Meier survivorship curve. Each data point represents the total percentage of degenerative patients who entered a given year of follow-up without clinical adjacent segment pathology. 
group, which would only serve to strengthen our findings of the difference between groups.

\section{Lumbar Spine Surgery}

Lumbar spine surgery for degenerative disc disease has been found to be a risk factor for CASP development in the cervical spine. ${ }^{17}$ This is presumably due to patients developing CASP also having a propensity to develop arthritic change elsewhere in the spine. Here, $7 \%$ of patients in the degenerative cohort also had undergone lumbar spine surgery due to degenerative disease, compared to $0 \%$ in the traumatic group. Although this did not reach statistical significance, there is a trend toward patients undergoing fusion for elective purposes also requiring lumbar spinal surgery for spondylosis. This was probably due to insufficient patient numbers, as supported by a post-hoc power analysis.

\section{RASP Development}

Reported rates of RASP are quite variable. Baba et al. demonstrated a $25 \%$ incidence of new canal stenosis at adjacent segments over an average follow-up of 8.5 years. ${ }^{18}$ Similarly, it has been shown that $25 \%$ of patients will develop new spondylosis, and an additional $25 \%$ will experience progression of pre-existing spondylosis. ${ }^{14}$ In our study, $20 \%$ of patients demonstrated evidence of RASP. Although there is wide variability in the literature $(10-84 \%),{ }^{8,19-25}$ this study's findings are on the lower end of what has been reported. Several explanations can account for this. Average radiographic follow-up was just over three years. With longer follow-up it is possible that this rate would increase. However, this is not necessarily borne out in the literature. For example, some studies report higher rates with less follow-up. ${ }^{20,22-25}$ Different studies have also made use of different radiographic scoring scales, many subject to varying degrees of inter-rater reliability. ${ }^{3,5,26-29}$ We used a radiographic scoring scale shown to be a reliable and objective tool for assessing cervical disc and facet degeneration; it was previously used in total disc arthroplasty trials. ${ }^{4,5}$ Furthermore, RASP development was found to be higher in the spondylotic than in the traumatic patient group. However, radiological follow-up between the two groups also varied. It is possible that with more uniform follow-up between the two groups RASP development would have been more similar as well. Many factors could account for this difference in follow-up, including a higher number of patients in the degenerative group requiring repeat operation. Patients requiring re-operation would have undergone more imaging studies at later time points. However, if they did not require repeat operation, only one post-operative radiograph at their first follow-up appointment would likely have been completed (accounting for a large range within the group). Furthermore, trauma patients have also been found to have a higher likelihood of being lost to followup, for numerous reasons. ${ }^{30,31}$ This could also in part explain the difference seen between the two groups' follow-up and RASP development.

\section{Limitations}

This is a retrospective study and as a result prone to innate biases. Moreover, it is a single center, single observer study. There were also technical differences between cohorts with respect to the type of operation, number of levels fused, and use of
Table 2: Univariate analysis results of factors related to CASP development

\begin{tabular}{l|c|c|c}
\hline Factor & $\begin{array}{c}\text { Traumatic } \\
\text { Cohort (\%) }\end{array}$ & $\begin{array}{c}\text { Degenerative } \\
\text { Cohort (\%) }\end{array}$ & P-value \\
\hline Repeat operation for CASP & $0 / 46(0.0)$ & $10 / 100(10.0)$ & 0.03 \\
\hline Lumbar spine surgery & $0 / 46(0.0)$ & $7 / 100(7.0)$ & 0.1 \\
\hline Radiological progression & $1 / 32(3.1)$ & $20 / 100(20.0)$ & 0.03 \\
\hline
\end{tabular}

instrumentation. Specifically, there was a minority of trauma patients who required multi-level fusions and were fused posteriorly, which was not accounted for in our analysis. However, previous studies show no definitive evidence to suggest that these factors play a role in CASP development. ${ }^{3,9,11,32,33}$ Finally, this study did not account for patient factors shown to influence CASP development such as the specific number of levels fused or smoking status. Accounting for all of these factors in the analysis with identification of independent risk factors through multivariate analysis would be ideal. A scoring scale to stratify a patient's risk of developing CASP based on their individual pre-operative risk factors could then be created in order to better counsel patients when obtaining informed consent. However, large sample sizes and/or increased effect sizes would be required in order to perform this kind of statistical analysis with subsequent internal and external validation.

\section{Conclusion}

ACDF is the preferred surgical approach for cervical spondylotic disease under most circumstances. As a consequence, however, some patients will go on to develop CASP and potentially require reoperation. The etiology and pathophysiology of CASP remain poorly understood. Cervical spondylotic patients were found to have a higher rate of repeat surgery for CASP and radiological adjacent segment degeneration than patients fused for traumatic instability. This finding suggests that the cause of CASP is likely more related to patient factors predisposing to progressive degenerative disease and not mechanical stress related factors.

\section{Disclosures}

Andrew Jack, Godefroy Hardy St-Pierre, and Andrew Nataraj do not have anything to disclose.

\section{REFERENCES}

1. Bohlman HH, Emery SE, Goodfellow DB, Jones PK. Robinson anterior cervical discectomy and arthrodesis for cervical radiculopathy. Long-term follow-up of one hundred and twenty-two patients. J Bone Joint Surg Am. 1993;75(9):1298-307.

2. Hilibrand AS, Robbins M. Adjacent segment degeneration and adjacent segment disease: the consequences of spinal fusion? Spine J. 2004;4(6 Suppl):190S-4S.

3. Hilibrand AS, Carlson GD, Palumbo MA, Jones PK, Bohlman HH. Radiculopathy and myelopathy at segments adjacent to the site of a previous anterior cervical arthrodesis. J Bone Joint Surg Am. 1999;81:519-28.

4. Walraevens J, Liu B, Meersschaert J, et al. Qualitative and quantitative assessment of degeneration of cervical intervertebral discs and facet joints. Eur Spine J. 2009;18:358-69. 
5. Coric D, Nunley PD, Guyer RD, et al. Prospective, randomized, multicenter study of cervical arthroplasty: 269 patients from the Kineflex|C artificial disc investigational device exemption study with a minimum 2-year follow-up: clinical article. J Neurosurg Spine. 2011;15:348-58.

6. Dinse GE, Lagakos SW. Nonparametric estimation of lifetime and disease onset distributions from incomplete observations. Biometrics. 1982;38(4):921-32.

7. Kaplan E, Meier P. Nonparametric estimation from incomplete observations. J Am Statist Assn. 1958;53:457-81.

8. Jawahar A, Cavanaugh DA, Kerr EJ 3rd, Birdsong EM, Nunley PD. Total disc arthroplasty does not affect the incidence of adjacent segment degeneration in cervical spine: results of 93 patients in three prospective randomized clinical trials. Spine J. 2010;10:1043-8.

9. Acikbas SC, Ermol C, Akyuz M, Tuncer R. Assessment of adjacent segment degeneration in and between patients treated with anterior or posterior cervical simple discectomy. Turkish Neurosurg. 2010;20:334-40.

10. Henderson CM, Hennessy RG, Shuey HM Jr., Shackelford EG. Posterior-lateral foraminotomy as an exclusive operative technique for cervical radiculopathy: a review of 846 consecutively operated cases. Neurosurg. 1983;13:504-12.

11. Lunsford LD, Bissonette DJ, Jannetta PJ, Sheptak PE, Zorub DS. Anterior surgery for cervical disc disease. Part 1: Treatment of lateral cervical disc herniation in 253 cases. J Neurosurg. 1980;53:1-11

12. Lunsford LD, Bissonette DJ, Zorub DS. Anterior surgery for cervical disc disease. Part 2: Treatment of cervical spondylotic myelopathy in 32 cases. J Neurosurg. 1980;53:9-12.

13. Smith GW, Robinson RA. The treatment of certain cervical-spine disorders by anterior removal of the intervertebral disc and interbody fusion. J Bone Joint Surg Am. 1958;40-A:607-24.

14. Gore DR, Sepic SB. Anterior cervical fusion for degenerated or protruded discs. A review of one hundred forty-six patients. Spine. 1984;9:667-71.

15. Williams JL, Allen MB Jr., Harkess JW. Late results of cervical discectomy and interbody fusion: some factors influencing the results. J Bone Joint Surg Am. 1968;50:277-86.

16. Williams JL AM, Harkes JW. Late results of cervical discectomy and interbody fusion: some factors influencing the results. J Bone Joint Surg. 1968;50A:277-86.

17. Nunley PD, Jawahar A, Cavanaugh DA, Gordon CR, Kerr EJ 3rd, Utter PA. Symptomatic adjacent segment disease after cervical total disc replacement: re-examining the clinical and radiological evidence with established criteria. Spine J. 2013;13:5-12.

18. Baba H, Furusawa N, Imura S, Kawahara N, Tsuchiya H, Tomita K. Late radiographic findings after anterior cervical fusion for spondylotic myeloradiculopathy. Spine. 1993;18:2167-73.

19. Maldonado CV, Paz RD, Martin CB. Adjacent-level degeneration after cervical disc arthroplasty versus fusion. Eur Spine J. 2011; 20(Suppl 3):403-7.
20. Kulkarni V, Rajshekhar V, Raghuram L. Accelerated spondylotic changes adjacent to the fused segment following central cervical corpectomy: magnetic resonance imaging study evidence. J Neurosurg. 2004;100(1 Suppl Spine):2-6.

21. Song KJ, Choi BW, Jeon TS, Lee KB, Chang H. Adjacent segment degenerative disease: is it due to disease progression or a fusion-associated phenomenon? Comparison between segments adjacent to the fused and non-fused segments. Eur. Spine J. 2011;20:1940-5.

22. Garrido BJ, Wilhite J, Nakano M, et al. Adjacent-level cervical ossification after Bryan cervical disc arthroplasty compared with anterior cervical discectomy and fusion. J Bone Joint Surg Am. 2011;93:1185-9.

23. Robertson JT, Papadopoulos SM, Traynelis VC. Assessment of adjacent-segment disease in patients treated with cervical fusion or arthroplasty: a prospective 2-year study. J Neurosurg Spine. 2005;3:417-23.

24. Kim SW, Limson MA, Kim SB, et al. Comparison of radiographic changes after ACDF versus Bryan disc arthroplasty in single and bi-level cases. Eur Spine J. 2009;18:218-31.

25. Park JB, Cho YS, Riew KD. Development of adjacent-level ossification in patients with an anterior cervical plate. J Bone Joint Surg Am. 2005;87:558-63.

26. Elsawaf A, Mastronardi L, Roperto R, Bozzao A, Caroli M, Ferrante L. Effect of cervical dynamics on adjacent segment degeneration after anterior cervical fusion with cages. Neurosurg Rev. 2009;32:215-24; discussion 24.

27. Goffin J, Geusens E, Vantomme N, et al. Long-term follow-up after interbody fusion of the cervical spine. J Spinal Disord Tech. 2004; 17:79-85.

28. Goffin J, van Loon J, Van Calenbergh F, Plets C. Long-term results after anterior cervical fusion and osteosynthetic stabilization for fractures and/or dislocations of the cervical spine. J Spinal Disord. 1995;8:500-8; discussion 499.

29. Ishihara H, Kanamori M, Kawaguchi Y, Nakamura H, Kimura T. Adjacent segment disease after anterior cervical interbody fusion. Spine J. 2004;4:624-8.

30. Aaland MO, Marose K, Zhu TH. The lost to trauma patient followup: a system or patient problem. J Trauma Acute Care Surg. 2012;73:1507-11.

31. Overton TL, Shafi S, Gandhi RR. Local access to care programs increase trauma patient follow-up compliance. Am J Surg. 2014;208:476-9.

32. Bydon M, Xu R, Macki M, et al. Adjacent segment disease after anterior cervical discectomy and fusion in a large series. Neurosurg. 2014;74:139-46; discussion 46.

33. Hannallah D, White AP, Fassett D, Kerr S, Whang PG, Hilibrand AS. Adjacent Level Degeneration in the Cervical Spine. Oper Tech Orthop. 2007;17:178-82. 